REVIEW ARTICLE

\title{
Bilateral Simultaneous Distal Biceps Rupture: A Case Report and Review of the Literature
}

\author{
John Reza Matthews, $M D^{1^{*}}$ and William Wind, $M D^{2}$ \\ ${ }^{1}$ Orthopaedic Surgery Resident, University of Buffalo, USA \\ ${ }^{2}$ University of Buffalo, USA
}

*Corresponding author: John Reza Matthews, B.S., M.D., University of Buffalo, Orthopaedic Surgery Resident, 257 Englewood Ave, Buffalo, NY 14214, USA, Tel: (520)-551-3044

\section{Introduction}

Overall, complete rupture of the distal biceps tendon is a rare injury with less than 500 cases reported in literature [1]. Distal biceps tendon tears frequently occur in males after the fifth decade of life as a result of forceful, sudden eccentric contraction [2]. Females are less frequently affected. Anabolic steroids may contribute to tendon pathology with one published case report [3]. In general, the dominant extremity is more commonly involved [4]. Simultaneous distal biceps tendon ruptures are much less common with only four reports published in literature [2,5-7]. The current study is a review of the literature and case report of simultaneous distal biceps tendon ruptures occurring during a pull up.

\section{Case Report}

The patient is a 45 -year-old right hand dominant male that presented to the office with chief compliant of bilateral elbow pain. He had no significant past medical or surgical history, but stated he was an avid weightlifter. He reported performing a pull up several days prior to presentation and while lowering down, experienced a "pop" in both elbows with immediate pain and cramping. Over the next day he noticed increased swelling and ecchymosis over both elbows extending to the forearms and a deformity in both arms, more pronounced on the left. He presented to an emergency room for evaluation and was discharged with instructions to follow up in the Orthopaedic office. The patient denied any previous injuries or problems with both elbows as well as anabolic steroid use.
On physical examination, visual inspection demonstrated residual swelling within the antecubital fossae and ecchymosis extending to the proximal lateral forearm of both elbows, but more extensive on the left. There was an obvious deformity of both biceps musculature with proximal retraction of the muscle belly on the left. The deformity was accentuated with resisted elbow flexion. Both elbows demonstrated localized tenderness directly over the biceps tendon. On the right, the biceps tendon was palpable in the antecubital fossa, but not on the left. Both elbows demonstrated normal range of motion with 0-135 degrees of flexion and 80 degrees of pronation/supination. Strength testing demonstrated $4+/ 5$ with supination and flexion on the right, $4 / 5$ on the left. The patient was otherwise neurovascularly intact distally.

Plain radiographs of both elbows were obtained which did not demonstrate any acute osseous abnormalities (Figure $1 \mathrm{~A}$ and Figure $1 \mathrm{~B}$ ). The patient underwent bilateral elbow Magnetic Resonance Imaging (MRI) which revealed bilateral full-thickness rupture of the distal biceps tendon with $5.9 \mathrm{~cm}$ retraction on the left and 1.4 $\mathrm{cm}$ retraction on the right (Figure $2 \mathrm{~A}$ and Figure $2 \mathrm{~B}$ ).

Treatment options were discussed with the patient including simultaneous bilateral surgery versus a staged operation. A staged operation was preferred to allow use of one arm for activities of daily living. The left biceps was addressed first due to the extent of tendon retraction as compared to the right. A single transverse incision was made $4 \mathrm{~cm}$ distal to the elbow flexion crease. Surgical exploration demonstrated complete

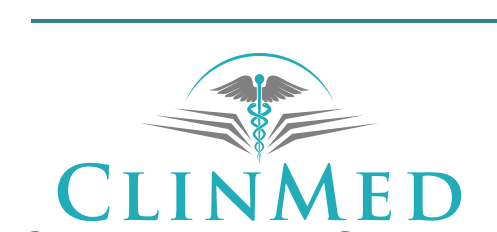

INTERNATIONAL LIBRARY 

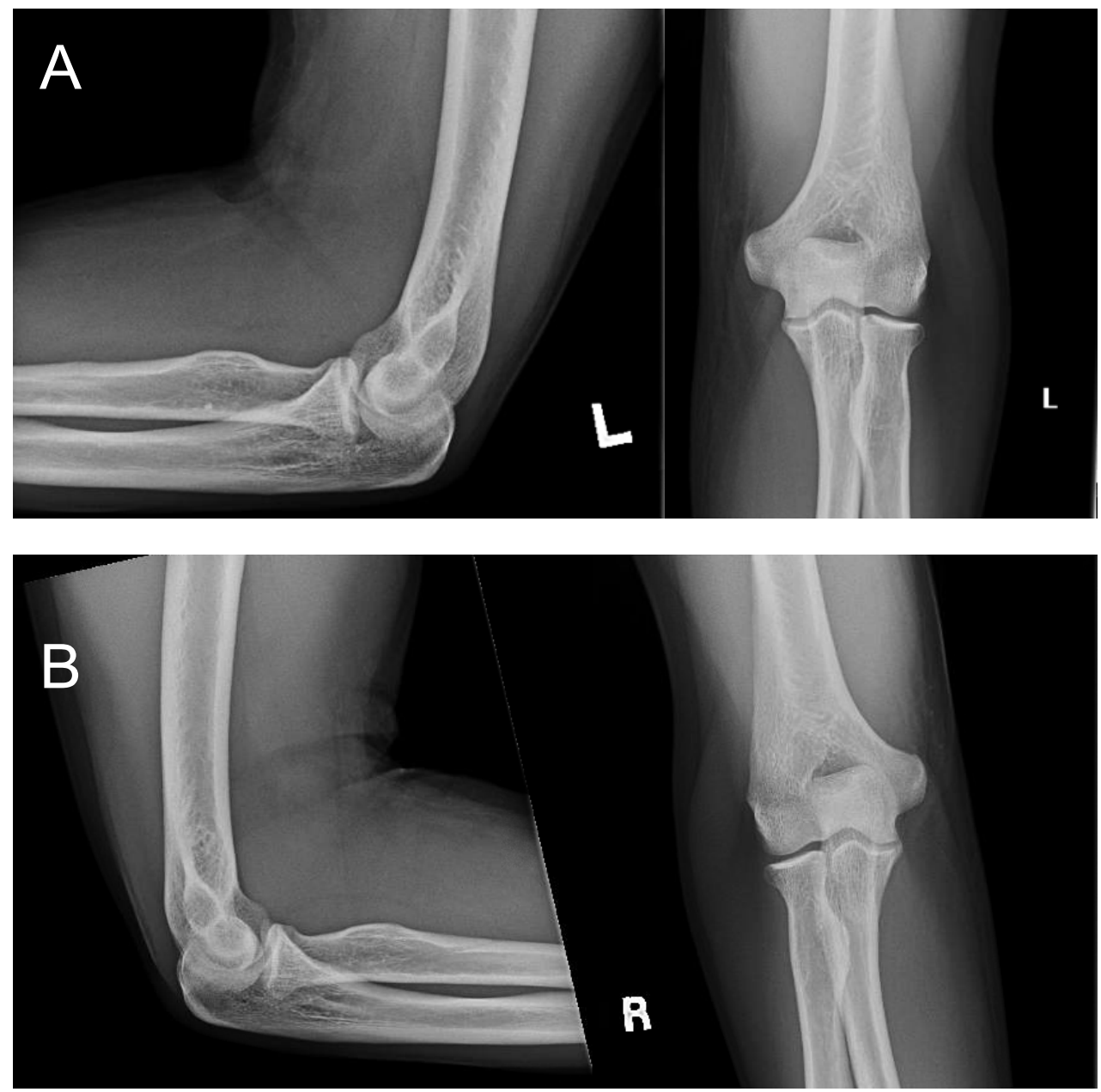

Figure 1: Figure $1 \mathrm{~A}$ and Figure 1B represent $A P$, lateral, and oblique $X$-rays of the left and right elbows respectively (A) AP, lateral and oblique X-rays of the left elbow; (B) AP, lateral, and oblique X-rays of the right elbow.

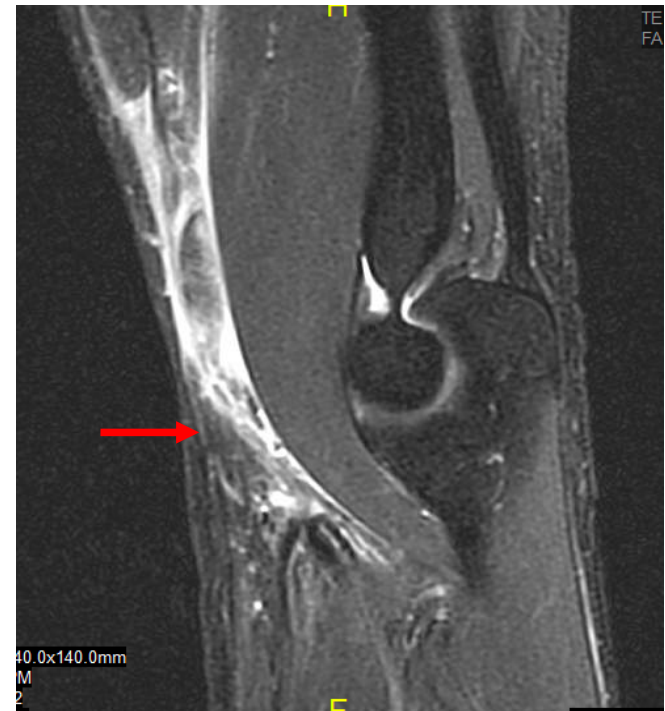

A

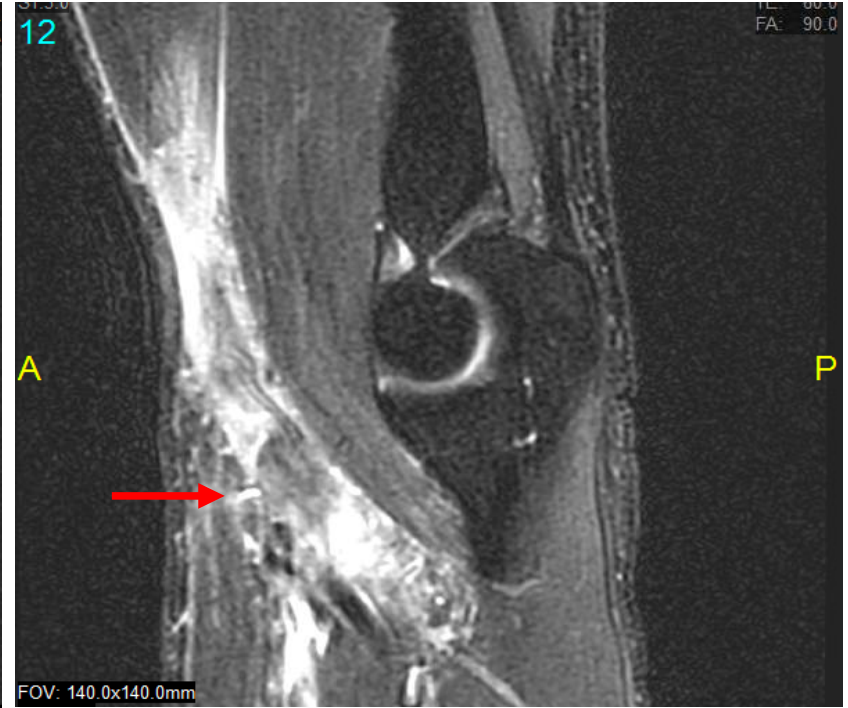

B

Figure 2: Figure 2A and Figure $2 \mathrm{~B}$ represents a sagittal MRI of the left elbow demonstrating a complete rupture of the distal biceps tendon with $5.9 \mathrm{~cm}$ retraction and surrounding edema; $(\mathrm{B})$ represents a sagittal $\mathrm{MRI}$ of the right elbow demonstrating a complete rupture of the distal biceps tendon with $1.4 \mathrm{~cm}$ retraction.

avulsion of the distal biceps tendon with significant proximal retraction. Once the tendon was identified and mobilized, an Arthrex fiber loop suture was placed in the distal stump. The radial tuberosity was then identified and verified under fluoroscopy. A $6 \mathrm{~mm}$ reamer was used to create a bone tunnel in the radial tuberosity 


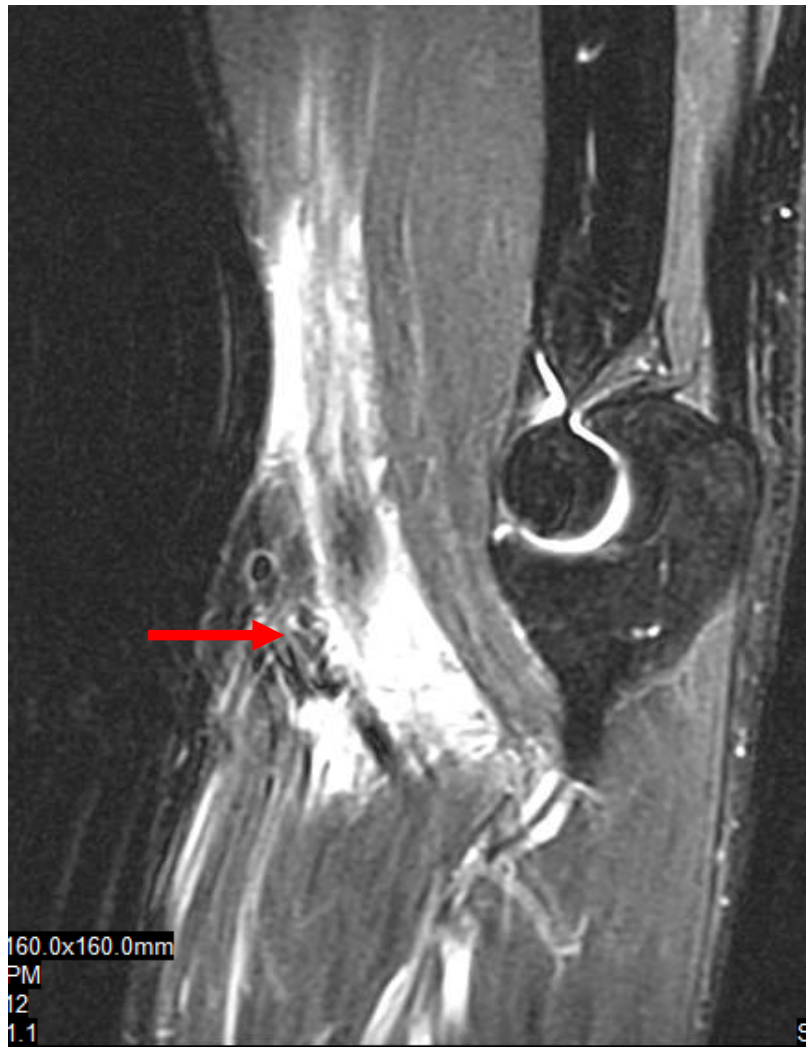

Figure 3: Represents a sagittal MRI of the right elbow demonstrating a complete rupture of the distal biceps tendon with $2.2 \mathrm{~cm}$ retraction.

to accommodate for the biceps tendon and an Arthrex distal biceps button. A tension slide technique was used to advance the biceps tendon into the previously created bone tunnel within the radial tuberosity. Once the tendon was docked into the bone tunnel, the suture was then looped around and passed again through the biceps tendon to complete the repair. The Arthrex biceps button position was verified under intra-operative fluoroscopy to be in an anatomic position. The elbow was then immobilized in a long arm posterior plaster splint for 1 week. At the 1 week follow up, the patient's incision was healing appropriately and he was transitioned to a sling with instructions to perform gentle passive elbow flexion exercises.

The patient returned to the office 3 weeks later for follow-up of his right elbow. He reported testing his right elbow at the gym performing a biceps curl when he felt a pop with increased pain. Repeat examination demonstrated mild swelling in the antecubital fossa but no significant ecchymosis. The biceps tendon was not able to be palpated in the antecubital fossa. A repeat MRI was obtained which demonstrated slightly increased retraction of the distal biceps tendon, measuring approximately $2.2 \mathrm{~cm}$ (Figure 3).

Surgery for the right side was performed 6 weeks following the left, approximately 8 weeks from date of injury. Again, a single incision $4 \mathrm{~cm}$ distal to the flexion crease was performed similar to the left side. The distal biceps tendon was identified proximally and had extensive scarring which was debrided for mobilization. The Arthrex fiber loop suture with distal biceps button was used for anchoring as previously done on the left and the patient immobilized in a long arm plaster splint for 1 week.

Post-operatively, the patient was transition to a sling 1 week after surgery on the right with gentle passive elbow flexion. Formal physical therapy for range of motion and gradual strengthening was initiated at 6 weeks post-operatively. At his latest follow up, 6 months following surgery on the left and four and a half months on the right, the patient had full range of motion on the left with 0-135 degrees of flexion, 80 supination/pronation as well a normal biceps musculature contour and full strength. On the right he had similar findings, with 0-130 flexion, 80 supination/pronation as well as full strength and muscle contour.

\section{Discussion}

Rupture of the distal biceps tendon is an uncommon injury with an incidence of 1.2 per 100,000 , mainly affecting males after the fifth decade of life $[2,8]$. Injury occurs secondary to a forceful eccentric contraction of the biceps tendon [9]. Treatment options of distal biceps tendon ruptures include non-operative or surgical repair. Non-operative intervention may result in $30 \%$ loss of flexion strength and $40-50 \%$ of supination strength [10]. Operative intervention includes primary direct repair or reconstruction in cases of delayed diagnosis due to significant tendon retraction and scarring [2].

Direct primary repair of distal biceps tendon ruptures results in satisfactory subjective and objective results [4]. Primary repair is usually best if completed within the first 6 weeks [7]. Chronic tears may require reconstruction of the tendon. Several investigators have reported satisfactory results with reconstruction options but variable strength recovery $[11,12]$. Kaplan, et al. reported satisfactory results using fascia lata autograft combined with ligament augmentation but had unpredictable return of strength [11]. Sanchez-Sotelo, et al. reported results on four patients with chronic distal biceps ruptures repaired with Achilles allograft and found comparable strength with flexion and supination in two patients but decreased in the remaining two patients [12].

Reports of simultaneous distal biceps tendon ruptures are limited in literature with only four published cases as seen in Table 1 [2,5-7]. Bilateral ruptures are challenging to address as all repair and reconstruction methods require a period of immobilization followed by gradual rehabilitation which can make self-care and activities of daily living difficult to manage. Three of the four previously reported cases were managed in a staged fashion with variable interval between the operations, although the surgical timing is unclear in one 
Table 1: Represents the prior studies returned on a literature review of simultaneous distal biceps ruptures.

\begin{tabular}{|c|c|c|c|c|c|c|c|c|}
\hline Study & $\begin{array}{l}\text { \# of } \\
\text { patients }\end{array}$ & Sex & Age & $\begin{array}{l}\text { Mechanism } \\
\text { of injury }\end{array}$ & $\begin{array}{l}\text { Time to Surgery } \\
\text { from DOI }\end{array}$ & Treatment & Result & Comments \\
\hline $\begin{array}{l}\text { Bayat, et al. } \\
{[6]}\end{array}$ & 1 & Male & 50 & Rock climbing & $\begin{array}{l}\text { Staged } 6 \text { months } \\
\text { apart }\end{array}$ & $\begin{array}{l}\text { Bilateral staged } \\
\text { reconstruction } \\
\text { with fascia lata } \\
\text { autograft }\end{array}$ & Satisfactory & $\begin{array}{l}\text { Presented } 2 \\
\text { years post } \\
\text { injury }\end{array}$ \\
\hline $\begin{array}{l}\text { Da Cambra, } \\
\text { et al. [7] }\end{array}$ & 1 & Male & 43 & Lifting drywall & $\begin{array}{l}\text { Unclear, staged } 6 \\
\text { weeks apart }\end{array}$ & $\begin{array}{l}\text { Bilateral staged } \\
\text { primary repair }\end{array}$ & Satisfactory & $\begin{array}{l}\text { Right LABCN } \\
\text { palsy }\end{array}$ \\
\hline $\begin{array}{l}\text { Rokito, et al. } \\
\text { [2] }\end{array}$ & 1 & Male & 51 & Preacher Curl & $\begin{array}{l}\text { Right - } 7 \text { weeks } \\
\text { Left - } 20 \text { weeks }\end{array}$ & $\begin{array}{l}\text { Right - primary } \\
\text { repair } \\
\text { Left - Achilles } \\
\text { allograft }\end{array}$ & Good & $\begin{array}{l}\text { 6-week delay in } \\
\text { presentation }\end{array}$ \\
\hline $\begin{array}{l}\text { Ferran, et al. } \\
\text { [5] }\end{array}$ & 1 & Male & 37 & Gymnastic & 5 days & $\begin{array}{l}\text { Simultaneous } \\
\text { primary repair }\end{array}$ & Excellent & \\
\hline
\end{tabular}

DOI: Date of Injury; LABCN: Lateral Antebrachial Cutaneous Nerve.

study $[2,6,7]$. Rokito, et al. reported good outcomes with comparable strength in a 51-year-old patient with a 6-week delay in presentation for bilateral distal biceps rupture that underwent primary repair on the right and Achilles tendon allograft reconstruction on the left [2]. Bayat, et al. reported satisfactory results in a 50-yearold climber that presented 2 years after his injury and underwent staged reconstruction of both distal biceps ruptures with fascia lata autograft [6]. DaCambra, et al. reported good outcomes with staged primary repair in a 43-year-old construction worker [7]. There is only one published case of simultaneous repair [5]. Ferran, et al. who reported a case of 37-year-old-male that sustained simultaneous bilateral distal biceps tendon ruptures during a gymnastic maneuver with satisfactory functional and clinical outcomes [5].

We present a case of a 45-year-old right hand dominant male that sustained bilateral simultaneous distal biceps tendon ruptures during a pull up. MRI evaluation demonstrated greater retraction of the left at 5.9 $\mathrm{cm}$ versus the right at $1.4 \mathrm{~cm}$. Despite the right being the patient's dominant extremity, given the clinical examination and MRI indicating less retraction it was felt a primary repair could still be performed on the right after addressing the left side. A staged primary repair was performed to allow use of one arm for activities of daily living. The left distal biceps tendon was repaired 2 weeks following date of injury and 8 weeks on the right. Post-operatively, the patient recovered well following each operation and had satisfactory results.

\section{Conclusion}

In summary, simultaneous distal biceps tendon ruptures are rare with only four cases reported in literature [2,5-7]. Distal biceps tendon injuries frequently occur as a result of forceful eccentric muscle contraction, as seen in this patient, during the descending portion of a pull up. Surgical planning is crucial to achieve optimal outcome for these injuries as chronic cases may require reconstruction options which have variable strength re- covery compared to primary repair. In this case, staged primary repair was performed addressing the more retracted side first. The left distal biceps tendon was primary repaired 2 weeks following injury date and the right at approximately 8 weeks. Staged intervention is a feasible option for simultaneous bilateral distal biceps ruptures since it allows use of one arm for activities of daily living. Satisfactory subjective and objective outcomes for both elbows were obtained.

\section{Conflict of Interest}

None of the authors or their immediate family have a financial or proprietary interest in the subject matter or materials discussed. No funding was obtained for this project.

There are no prior or duplicate submission of this work elsewhere.

The manuscript has been read and approved by all authors and each author believes that the manuscript represents honest work.

\section{References}

1. Rantanen J, Orava S (1999) Rupture of the distal biceps tendon. A report of 19 patients treated with anatomic reinsertion, and a meta-analysis of 147 cases found in the literature. Am J Sports Med 27: 128-132.

2. Rokito AS, lofin I (2008) Simultaneous bilateral distal biceps tendon rupture during a preacher curl exercise: a case report. Bull NYU Hosp Jt Dis 66: 68-71.

3. Visuri T, Lindholm H (1994) Bilateral distal biceps tendon avulsions with use of anabolic steroids. Med Sci Sports Exerc 26: 941-944.

4. Leighton MM, Bush-Joseph CA, Bach BR (1995) Distal biceps brachii repair. Results in dominant and nondominant extremities. Clin Orthop Relat Res 317: 114-121.

5. Ferran NA, Sher D (2016) Bilateral Primary Repair of Simultaneous Bilateral Distal Biceps Rupture. Bull Hosp Jt Dis 74: 234-236.

6. Bayat A, Neumann L, Wallace WA (1999) Late repair of simultaneous bilateral distal biceps brachii tendon avulsion with fascia lata graft. Br J Sports Med 33: 281-283. 
7. Dacambra MP, Walker RE, Hildebrand KA (2013) Simultaneous bilateral distal biceps tendon ruptures repaired using an endobutton technique: a case report. J Med Case Rep 7: 213.

8. Green JB, Skaife TL, Leslie BM (2012) Bilateral distal biceps tendon ruptures. J Hand Surg Am 37: 120-123.

9. Strauch RJ (1999) Biceps and triceps injuries of the elbow. Orthop Clin North Am 30: 95-107.

10. Morrey BF, Askew LJ, An KN, Dobyns JH (1985) Rupture of the distal tendon of the biceps brachii. A biomechanical study. J Bone Joint Surg Am 67: 418-421.
11. Kaplan FT, Rokito AS, Birdzell MG, Zuckerman JD (2002) Reconstruction of chronic distal biceps tendon rupture with use of fascia lata combined with a ligament augmentation device: a report of 3 cases. J Shoulder Elbow Surg 11: 633636.

12. Sanchez-Sotelo J, Morrey BF, Adams RA, O'Driscoll SW (2002) Reconstruction of chronic ruptures of the distal biceps tendon with use of an achilles tendon allograft. J Bone Joint Surg Am 84: 999-1005. 